\title{
Posttranslational modifications of HBV core protein
}

\author{
B. LUBYOVÁ, J. WEBER
}

\begin{abstract}
Institute of Organic Chemistry and Biochemistry of the Czech Academy of Sciences, Flemingovo nám. 2, 16610 Prague 6, Czech Republic
\end{abstract}

\begin{abstract}
Summary. - Infection with hepatitis B virus (HBV) often leads to development of chronic liver disease. In fact, $10 \%$ of infected adults and almost $90 \%$ of infected infants develop chronic hepatitis B associated with severe liver diseases, including acute liver failure, liver cirrhosis or hepatocellular carcinoma. At present there is no effective cure for chronic hepatitis B. The current treatment of chronically infected patients is long-term, expensive and relies on treatment with nucleos(t)ide analogs in combination with immune therapies, that frequently lead to adverse side effects. Recently, the National Institute of Health proposed strategic plan for Trans-NIH research to cure hepatitis B. The key priority is better understanding of HBV life cycle and its interactions with host cell. Due to the fact that HBV is a small double stranded DNA virus encoding only a limited number of proteins, HBV replication widely relies on host cell pathways and proteins. As demonstrated by numerous reports, HBV core protein $(\mathrm{HBc})$ which is the main component of viral nucleocapsid, plays multiple roles in HBV life cycle and is engaged in many protein interaction networks of the host cell. Several recent studies have shown that HBV proteins can be modified by different types of posttranslational modifications (PTMs) that affect their protein-protein interactions, subcellular localization and function. In this review, we discuss diverse PTMs of HBc and their role in regulation of $\mathrm{HBc}$ function in the context of $\mathrm{HBV}$ replication and pathogenesis.
\end{abstract}

Keywords: hepatitis B virus; posttranslational modifications; HBV core protein; phosphorylation; ubiquitination; arginine methylation

\section{Introduction}

Chronic infection with hepatitis B virus (HBV) is associated with severe liver diseases including fibrosis, cirrhosis, hepatocellular carcinoma or acute liver failure (Lavanchy, 2004; Torres and Davila, 2012). According to

E-mail:barbora.lubyova@uochb.cas.cz,phone: +420-220183211; jan.weber@uochb.cas.cz, phone: +420-220183420.

Abbreviations: $A R D=$ arginine rich domain; $\operatorname{cccDNA}=$ covalently closed circular DNA; CDK2 = cyclin-dependent kinase 2; $\mathrm{CK} 2$ = casein kinase 2; CTD = C-terminal domain; $\mathrm{HBV}=$ hepatitis $\mathrm{B}$ virus; $\mathrm{HBc}=\mathrm{HBV}$ core protein; $\mathrm{MMA}=$ monomethyl arginine; NTD = N-terminal domain; $\mathrm{PKA}=$ protein kinase $\mathrm{A} ; \mathrm{PKC}=$ protein kinase $\mathrm{C}$; PLK1 = polo-like-kinase 1; PRMT = protein arginine methyltransferase; $\mathrm{PTM}=$ posttranslational modification; rcDNA = relaxed circular DNA; sDMA = symmetric dimethylarginine; $\mathrm{SRPK}=$ serine arginine protein kinase; $\mathrm{Ubl}$ = ubiquitin-like; UPS = ubiquitin proteasome system
World Health Organization, more than 250 million people worldwide are chronically infected with HBV. Current therapies which rely on nucleos(t)ide analogues or immunotherapy are not able to eradicate the virus due to the persistence of viral episomal DNA (also known as covalently closed circular DNA, cccDNA) in the nuclei of infected cells (Allweiss and Dandri, 2017; Yang and Kao, 2014).

Hepatitis B virus (HBV) is a small, enveloped virus with a 3.2-kb-long, partially double-stranded circular DNA genome. It encodes only four overlapping open reading frames, that are transcribed into 6 RNAs and translated to 7 proteins, e.g. precore $(\mathrm{HBe} A g)$, core $(\mathrm{HBc})$, viral polymerase $(\mathrm{P})$, envelope/surface proteins (S, M and L) and $\mathrm{X}$ protein (HBx).

HBV core protein (HBc, also called core antigen, $\mathrm{HBcAg}$, $\mathrm{Cp}$, or p21.5) participates in almost every step of HBV life cycle (Diab et al., 2018). Upon HBV entry, the viral core nucleocapsid is released from the endosome to the cyto- 
plasm and is transported to the nucleus, where it binds the nuclear pore complex (Rabe et al., 2003; Schmitz et al., 2010). In nucleus, the relaxed circular viral DNA (rcDNA) is repaired by host enzymes and forms a covalently closed circular DNA (cccDNA) with a typical chromatin structure consisting of histone proteins and liver-enriched as well as ubiquitous transcription factors and nuclear receptors (Koniger et al., 2014; Mohd-Ismail et al., 2019). In nucleus, HBc was suggested to regulate transcription of HBV RNAs through direct binding to cccDNA minichromosome and recruitment of cellular histone acetyltransferases (Chong et al., 2017). In the cytoplasm, HBc participates in RNA encapsidation, reverse transcription, nucleocapsid assembly and viral release (Zlotnick et al., 2015).

Depending on HBV genotype (A to J), core protein is 183 or 185 amino acids (aa) long (in this review referred to as 183 -aa and 185-aa HBc variant, respectively), and has approximate molecular mass of $21.5 \mathrm{kDa}$. Structurally, the $\mathrm{HBc}$ protein could be divided to $\mathrm{N}$ - and C-terminal domains that are connected with a 9 amino acids linker region. N-terminal domain (NTD), also known as assembly domain, encompasses amino acids from 1 to 140 , and is necessary for capsid assembly (Birnbaum and Nassal, 1990; Gallina et al., 1989). The icosahedral HBV capsid is composed of 120 dimers (triangulation number $\mathrm{T}=4$ ) of core protein. C-terminal domain (CTD) spanning amino acids from 150 to 183 (or 185) is involved in encapsidation of viral polymerase and pgRNA and thus facilitates its reverse transcription (Beames and Lanford, 1993; Hatton et al., 1992; Nassal, 1992). C-terminal region consists of four arginine rich subdomains (ARD I to IV). ARDI and ARDIII were recently shown to associate with two co-dependent nuclear localization signals, while ARDII and ARDIV behave like two independent nuclear export/ cytoplasm retention signals (Li et al., 2010). The versatile roles of core protein in pgRNA and DNA encapsidation, subcellular transport of nucleocapsid including binding to nuclear pore and release of rcDNA to nucleoplasm were shown to be facilitated by dynamic phosphorylation and de-phosphorylation events occurring predominantly on serine residues within CTD (Heger-Stevic et al., 2018; Zhao et al., 2018). The linker region (aa 141-149) was previously assumed to merely serve as a spacer between NTD and CTD. However, a recent study revealed that high degree of sequence conservation in this region is required for RNA packaging, and viral DNA synthesis (Liu et al., 2018).

Posttranslational modifications (PTMs) are critical in regulating the folding of proteins, their stability, targeting to specific subcellular compartments, interaction with ligands or other proteins, and their catalytic activity or the signaling function (Duan and Walther, 2015). PTMs are among the first events employed by eukaryotic cells to react to infection (Ribet and Cossart, 2010). PTMs, particularly phosphorylation, acetylation, ubiquitination, SUMOylation, or NEDDylation were shown to play important role in both restricting and supporting of HBV replication (Kong et al., 2019; Yang, 2018). The focus of this review are posttranslational modifications of HBV core/ capsid protein, particularly C-terminal serine phosphorylation, ubiquitination and arginine methylation, and their role in core protein function, subcellular trafficking and ability to assemble nucleocapsid.

\section{HBc and phosphorylation}

Phosphorylation is one of the most abundant and important reversible post-translational modifications of cellular as well as viral proteins. The human genome contains over 500 protein kinases and about $30 \%$ of all human proteins may be phosphorylated (Manning et al., 2002). In the world of viruses to obtain such statistics is difficult, but many large DNA viruses encode their own viral kinases (Jacob et al., 2011) and small DNA viruses and RNA viruses utilize various cellular kinases to complete their life cycle (Jakubiec and Jupin, 2007; Keating and Striker, 2012; Lenard, 1999). The addition or removal of phosphate group can dramatically change the protein structure and its function. Indeed, change of the phosphorylation state can modulate enzymatic activity, signal pathways, cellular location, protein stability and/or interaction with other cellular and viral proteins (Cohen, 2000; Jakubiec and Jupin, 2007; Keating and Striker, 2012). The smaller the genome the better the virus utilizes the cell host kinase and phosphatase machinery and its proteins have to assume different functions based on their phosphorylation status. The HBV and specifically the HBc is a very good example of the synergy of both strategies.

As the small-sized HBV genome encodes neither a protein kinase nor phosphatase, HBc depends on cellular kinases and phosphatases for phosphorylation and dephosphorylation reaction. In this respect, several kinases were suggested, among others protein kinase C (PKC) (Kann and Gerlich, 1994; Wittkop et al., 2010), casein kinase 2 (CK2) (Enomoto et al., 2006), glyceraldehyde-3-phosphate dehydrogenase protein kinase (GAPD-PK) (Duclos-Vallee et al., 1998), a 46-kDa serine protein kinase (Kau and Ting, 1998), serine arginine protein kinase 1 and 2 (SRPK1/2) (Daub et al., 2002; Heger-Stevic et al., 2018), cyclin-dependent kinase 2 (CDK2) (Ludgate et al., 2012), and polo-like-kinase 1 (PLK1) (Diab et al., 2017). The kinases have a multitude of potential targets as HBc protein sequence contains 36 amino acids (almost 20\%) as potential acceptors of phosphate group. The 18 serines, 13 threonines, and 5 tyrosines are mostly conserved across different genotypes (Hayer et al., 2013; Jung et al., 2014). The C-terminal domain of HBc 


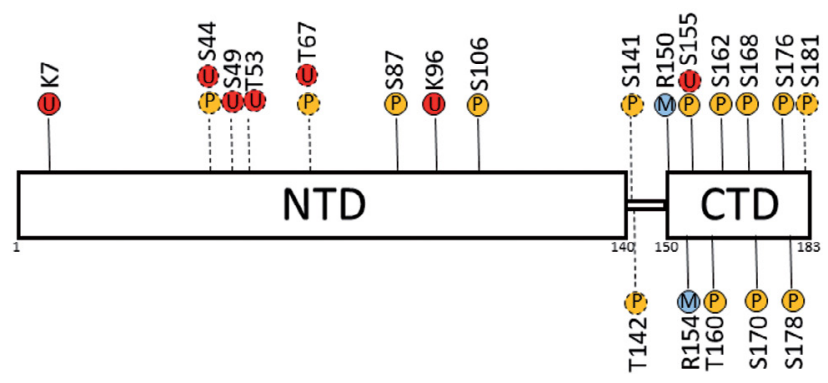

Fig. 1

Sites of posttranslational modifications (PTMs) on HBV core protein (HBc)

The schematic representation of the 183-amino acid variant of $\mathrm{HBC}$ showing the amino acids subjected to various PTMs, including phosphorylation, ubiquitination, and arginine methylation. Dashed lines represent PTMs detected only by mass spectrometry analysis. NTD, N-terminal domain; CTD, C-terminal domain; P, phosphorylation; $\mathrm{U}$, ubiquitination; $\mathrm{M}$, arginine methylation.

stands out as it contains three SP (serine/proline) recognition sequences and CTD was shown to be essential for pgRNA encapsidation, viral DNA synthesis, subcellular localization and virion secretion (Diab et al., 2018; Liu et al., 2015; Yang, 2018).

Mutagenesis analyses and mass spectrometry of $\mathrm{HBc}$ identified several hydroxy amino acids as target for phosphorylation (Fig. 1). The serine mutagenesis at position 155, 162, 170 (157, 164, 172 in a 185-aa HBc variant) confirmed that phosphorylation occurs on each of the SP recognition sites (Daub et al., 2002; Jung et al., 2014; Melegari et al., 2005). Serine at position 155 was reported not essential for RNA encapsidation and DNA replication (Gazina et al., 2000; Lan et al., 1999; Melegari et al., 2005) albeit $\mathrm{HBc}$ mutant with Ser-to-Ala at position 155 failed to produce mature relaxed circular DNA form of the HBV genome (Melegari et al., 2005). In addition, independent contribution of Ser155 to minus-strand DNA elongation, primer translocation, circularization and plus-strand DNA elongation was observed (Lewellyn and Loeb, 2011). Finally, Su et al. emphasized importance of Ser at 155 by showing that the Ser155 can regulate charge imbalances in the interior of capsid (Su et al., 2016). Less controversial is the importance of Ser162 and Ser170 that were shown to be critical for RNA encapsidation and DNA synthesis (Gazina et al., 2000; Lan et al., 1999; Lewellyn and Loeb, 2011; Melegari et al., 2005). Based on the detailed mutagenesis analysis, Ser162 plays more significant role in RNA packaging than Ser170, as presence of Ser162 in the context of HBc containing Ser155Ala and Ser170Pro was sufficient for efficient encapsidation (Melegari et al., 2005) and mutation of Ser162 showed the biggest decrease in encapsidation efficiency (Gazina et al., 2000).
Both serines (at position 162 and 170) seem to be equally essential for HBV DNA synthesis (Lan et al., 1999; Melegari et al., 2005), although analysis of individual steps of DNA synthesis favors more prominent role of Ser162 (Lewellyn and Loeb, 2011).

Next to these major phosphorylation sites, additional minor phosphor-acceptor sites at S/T positions in CTD were identified (Daub et al., 2002; Diab et al., 2017; HegerStevic et al., 2018; Jung et al., 2014; Lubyova et al., 2017). Further mutations of Ser176 and Ser178 (178 and 180 in a 185-aa HBc variant) to alanines in HBc-Ser155/162/170Ala triple mutant almost completely removed all residual SRPK-mediated phosphorylation (Daub et al., 2002). Phosphorylation of Ser176 and Ser178 was confirmed using $\left[{ }^{32} \mathrm{P}\right]$ orthophosphate labelling of Huh7 cells expressing $\mathrm{HBc}$ followed by immunoprecipitation with anti-HBc antibody (Jung et al., 2014). In the same study, phosphorylation on threonine 160 (162 for 185-aa HBc) was described and mutation to alanine significantly reduced minus-strand, plus-strand and rc DNA synthesis (Jung et al., 2014). Recently, polo-like-kinase 1(PLK1) was shown to directly bind to $\mathrm{HBc}$ and to phosphorylate Ser176, Ser178 together with Ser168 (Diab et al., 2017). In addition, they observed supportive role of PLK1 enzyme on nucleocapsid formation and capsid-assisted reverse transcription of pgRNA (Diab et al., 2017). Further confirmation of multiple phosphorylated hydroxy amino acids in CTD of HBc was provided by our mass spectrometry analysis of wild type (wt) HBc and Arg-to-Ala HBc mutants in ARDs (Lubyova et al., 2017). Using anti-HA immunoprecipitation coupled to mass spectrometry we identified phosphorylation on all eight hydroxy amino acids in CTD of HBc (Lubyova et al., 2017). Finally, the extensive phosphorylation of CTD of $\mathrm{HBc}$ was also corroborated by the work of Heger-Stevic and colleagues (Heger-Stevic et al., 2018). With combination of Phos-tag SDS-PAGE electrophoresis, mass spectrometry and mutagenesis, they identified seven out of eight possible phosphoacceptor sites - Ser155, Thr160, Ser162, Ser168, Ser170, Ser176, and Ser178 as targets for SRPK1. The sole exception was Ser181 (Heger-Stevic et al., 2018).

Literature about phosphorylation outside of the CTD of $\mathrm{HBc}$ is scarce. Serine 87 in genotype $\mathrm{C}$ of $\mathrm{HBc}$ is phosphorylated in vitro by PKA and this phosphorylation facilitates capsid assembly (Kang et al.,2006). Interestingly, Ser87 is not conserved among the different genotypes and in adw subtype is replaced by Asp87 (Jung et al., 2014). Similarly, Ser106 in genotype $\mathrm{C}$ of $\mathrm{HBc}$ was reported to be in vitro phosphorylated by $\mathrm{PKC}$, thus increasing capsid assembly and stability (Kang et al., 2008). In addition, phosphorylation at Ser44, Thr67, Ser141, and Thr142 was detected by MS analysis, but importance of these modifications awaits further studies (Lubyova et al., 2017). 
There is undisputable role of phosphorylation and dephosphorylation of HBc protein in many steps of HBV life cycle. Recent advancements showed that during viral assembly there is a need for tightly coordinated spatial and temporal interplay between phosphorylation and dephosphorylation reactions (Heger-Stevic et al., 2018; Zhao et al., 2018). It was previously described that HBV and duck HBV core proteins are hyperphosphorylated in immature intracellular nucleocapsids while mature and secreted virions contain hypophosphorylated HBc (Basagoudanavar et al., 2007; Perlman et al., 2005; Pugh et al., 1989; Su et al., 2016; Zhao et al., 2018). In addition, Ning and colleagues demonstrated that CTD of HBc in empty virions is highly phosphorylated (Ning et al., 2017). Moreover, recent study using immunoblotting with antibodies capable to differentiate between hyper and hypophosphorylated $\mathrm{HBc}$ has shown that $\mathrm{HBc}$ dephosphorylation occurs simultaneously with pgRNA packaging (Zhao et al., 2018). Finally, with increasing $\mathrm{HBc}$ serine dephosphorylation, the empty capsids can be converted into RNA-containing capsids (Su et al., 2016). Taken together, these results prompted Heger-Stevic and colleagues to formulate hypothesis about the role of dephosphorylation during virion assembly (Heger-Stevic et al., 2018). Nonphosphorylated CTDs of $\mathrm{HBc}$ have highest maximal positive charge from four ARDs and were shown to lead to nonspecific RNA packaging (Ludgate et al., 2016). Phosphorylation on all hydroxy amino acids will neutralize the positive charge but cause generation of empty capsids (Ning et al., 2017). Heger-Stevic and colleagues propose that the pgRNA/P protein complex carries also a phosphatase activity that can partially dephosphorylate nearby HBc-CTDs. This would restore their RNA binding potential and dephosphorylation would slowly spread onto neighboring HBc dimers until the whole shell is completed (Heger-Stevic et al., 2018). Only partial dephosphorylation will maintain enough phosphorylated CTD of HBc that is required during early phases of reverse transcription for the synthesis of the minus-strand DNA (Basagoudanavar et al., 2007). Further dephosphorylation is necessary during the production of negatively charged mature rcDNA to maintain electrostatic homeostasis (Chua et al., 2010; Newman et al., 2009; Su et al., 2016). Finally, new virion with fully dephosphorylated nucleocapsid is secreted from cells and ready to infect new cells. Heger-Stevic and colleagues further hypothesized that upon infection of new cell the uncoating process could start with destabilization of nucleocapsid by surge of negative charge due to the CTD re-phosphorylation and completion of plus-strand DNA (Heger-Stevic et al., 2018).

Phosphorylation of $\mathrm{HBc}$ is also essential for import of viral genomes to the nucleus. It was demonstrated that only phosphorylated HBc can bind to the nuclear pore by the importin-mediated pathway (Kann et al., 1999). Furthermore, HBc phosphorylation and dephosphorylation regulates the chaperone activity of CTD, thus influence the annealing, strand displacement, and RNA cleavage (Chen et al., 2011; Chu et al., 2014; Wang et al., 2012). In addition, phosphorylation can influence further interaction between $\mathrm{HBc}$ and other viral or cell factors, e.g. interaction with cAMP response element or host cell proteins (Ludgate et al.,2011; Xiang et al., 2015). Finally, phosphorylation is important for capsid maturation and stability (Ludgate et al., 2016; Selzer et al., 2015; Su et al., 2016).

To translate all the recent progress concerning the role of phosphorylation and dephosphorylation in the HBV life cycle into the novel targets for antiviral therapy, the corresponding kinases and phosphatases have to be identified. As mentioned above several kinase candidates have been proposed through the years. It is quite possible that more than one kinase and/or phosphatase may be involved to manage the plethora of HBc activity. Recently, Diab and colleagues proposed such cooperation between kinases (Diab et al., 2017). In a recent study, they have identified polo-like kinase 1 as a proviral host factor that phosphorylates Ser168, Ser176, and Ser178, but requires prior phosphorylation of 3 HBc SP sites by CDK2 (Diab et al., 2017). It was shown that CDK2 can phosphorylate HBc both in vitro and in vivo (Ludgate et al.,2012). Interestingly, the CDK2 inhibitors had no detectable effect on HBV replication (Ludgate et al., 2012). Conversely, inhibition of PLK1 led to impaired HBV replication in liver of humanized mouse model (Diab et al., 2017). Other kinase candidates proposed are SRPK1, PKA and/or PKC. Heger-Stevic and colleagues implicated these kinases in CTD phosphorylation. Using mutagenesis experiments coupled with mass spectrometry, they detected up to seven phosphorylation sites in the case of SRPK1 and three phosphorylation sites in the case of PKA and PKC (Heger-Stevic et al., 2018). On the other hand, there are also conflicting reports showing that inhibition of PKC and PKA does not have an effect on CTD phosphorylation(Ludgate et al.,2012). Moreover, even though overexpression of SRPK1 reduced HBV replication; it was independent of HBc phosphorylation (Zheng et al., 2005). There is clear evidence of $\mathrm{HBc}$ phosphorylation importance for HBV replication but more research is necessary to elucidate the exact kinases and phosphatases involved in this process.

\section{HBc and ubiquitination}

Ubiquitination is a type of reversible posttranslational modification, which involves covalent attachment of one or more ubiquitin moieties to substrate proteins (Hershko and Ciechanover, 1998; Swatek and Komander, 
2016). This process most commonly binds the last amino acid of ubiquitin (glycine 76) to an epsilon-amino group $\left(\varepsilon-\mathrm{NH}_{3}{ }^{+}\right)$of lysine residue on the substrate (Mattiroli and Sixma, 2014). Recently, there is also increasing evidence of so-called non-canonical ubiquitination where non-lysine residues are ubiquitinated using non-amine groups, such as the sulfhydryl group on cysteine, and the hydroxyl group on threonine and serine (Kravtsova-Ivantsiv and Ciechanover, 2012; McClellan et al., 2019; McDowell and Philpott, 2013).

Ubiquitin is a 76-amino acid protein, that carries seven lysine residues, all of which can be further ubiquitinated and thus give rise to multi-ubiquitin chains (Wiborg et al., 1985). Attachment of a single ubiquitin to a substrate protein leads to protein mono-ubiquitination that usually regulates binding properties of a target protein. Connection of several ubiquitin molecules results in formation of polyubiquitin chains with distinct conformations. In a ubiquitin chain, ubiquitin moieties can be conjugated through one of their seven lysine residues (K6, K11, K27, $\mathrm{K} 29, \mathrm{~K} 33, \mathrm{~K} 48$ and K63), or the N-terminal methionine residue (M1). The most common polyubiquitination consists of Lys48-, Lys11-, or heterotypic branched Lys48/ Lys11-linked chains that usually target proteins for proteasomal degradation (Akutsu et al., 2016). Non-degradative ubiquitin chains, including Lys63-, Lys6-, Lys33-, Lys27and Lys29-linked chains may play role in various cellular processes and pathways, like immune regulation, intracellular trafficking, endocytosis, DNA damage repair or Wnt, TNF and NFKB signaling (Akutsu et al., 2016; Swatek and Komander, 2016).

Process of ubiquitination requires three types of enzyme: ubiquitin-activating enzymes, ubiquitinconjugating enzymes, and ubiquitin ligases, known as E1s, E2s, and E3s, respectively. While in human cells there are only few E1 and E2 enzymes, the final step of ubiquitination cascade is catalyzed by one of hundreds E3 ubiquitin ligases. They serve as the substrate recognition modules and are capable of interaction with both E2 and a substrate (Scheffner et al., 1995).

It is well-known that host cells often employ the ubiquitin proteasome system (UPS) as anti-viral mechanism to target viral proteins for degradation and to restrict viral replication (Aviel et al., 2000; Chiramel et al., 2019; Lata et al., 2018). Numerous reports have demonstrated that HBV proteins, namely $\mathrm{HBx}$, polymerase or $\mathrm{HBc}$, could be directly ubiquitinated and targeted for proteasome-mediated degradation (Kim et al., 2003; Kong et al., 2019; Ling et al., 2008; Wang et al., 2011; Zhao et al., 2011). The first evidence that HBc could be degraded by ubiquitin-proteasome pathway was provided by Qian and colleagues (Qian et al., 2012). They demonstrated that NIRF E3 ubiquitin-protein ligase (Np95/ICBP90-like RING finger protein, or UHRF2) can directly interact with $\mathrm{HBc}$ and promote its proteasome-mediated degradation. Decrease of HBc protein level led to reduced amount of HBV particles. Conversely, the NIRF knock-down resulted in increased endogenous $\mathrm{HBc}$ levels in HepG2.2.15 cells (Qian et al., 2012). Nevertheless, a direct NIRF-mediated Ub-chain conjugation to $\mathrm{HBc}$ has not been demonstrated. In the follow-up study, NIRF has also been shown to inhibit HBV replication as well as secretion of HBs and HBe antigens in HBV-transfected HepG2 cells and in mouse model that expressed HBV (Qian et al., 2015). A restricting effect of NIRF on HBV replication was mediated both by targeting $\mathrm{HBc}$ for degradation and reducing acetylation of cccDNA-bound $\mathrm{H} 3$ histones.

HBV core protein contains only two lysine residues at position 7 and 96 (K7, K96, Figure 1) that are well conserved across all HBV strains and could potentially serve as acceptor sites for modification by ubiquitin. In addition, $\mathrm{HBc}$ contains two adjacent L-domain-like sequences located within a single motif: ${ }_{129}$ PPAYRPPNAP $^{138}$ (Garcia et al., 2013; Rost et al., 2006). PPAY motif was shown to interact with the NEDD4 E3 Ub-protein ligase, that may target $\mathrm{HBc}$ for ubiquitination and subsequent UIM-(ubiquitin interaction motif) dependent recognition by gamma2adaptin, a putative endosomal sorting and trafficking adaptor of the adaptor protein complex family. Indeed, cotransfection of HBc-Y132A mutant together with NEDD4 expression plasmid and core-negative pHBV.C replicon into Huh7 cells abolished the NEDD4 interaction with $\mathrm{HBc}$ and resulted in a replication-defective virus that did not assemble infectious virions (Rost et al., 2006). These data imply that PPAY sequence is a genuine L-domain-like motif that may serve as a docking site for recruitment of NEDD4 as well as other host factors that regulate viral release (Garcia et al., 2013; Rost et al., 2006). Core lysine residue at position 96 (Lys96) was identified to be essential for both gamma2-adaptin-recognition and virus maturation. Mutation of Lys96 residue to alanine (K96A) led to impaired assembly phenotype, further supporting the role of Lys96 in virion production (Rost et al., 2006). Nevertheless, a direct evidence of $\mathrm{HBc}$ protein ubiquitination mediated by NEDD4 ubiquitin ligase has been elusive. The possible explanation for lack of $\mathrm{HBc}$ ubiquitination detection could be the fact that only a small fraction of $\mathrm{HBc}$ pool is transiently modified by ubiquitination at any given time. In contrary to a previous report, Garcia et al. (Garcia et al., 2009) questioned a potential role of Lys96 ubiquitination in HBV maturation and release. In their experiments, mutation of Lys7 and Lys96 to arginine, K7R and K96R, which compared to alanine is more conserved, did not affect either virus replication or virion release (Garcia et al., 2009). However, mutation of Lys96 to arginine altered the nuclear-cytoplasmic distribution of core, leading to an accumulation in the nucleolus. 
In our study we demonstrated that HBc protein could be covalently modified by ubiquitination at Lys7 in transfected hepatoma HepG2-NTCP cells (Lubyova et al., 2017). Lys-to-Arg mutation at position 7 (K7R) resulted in decreased levels of mono- and polyubiquitinated HBc. In addition, the proteomic data collected by mass spectrometry analysis of $w t \mathrm{HBc}$ and Lys-to-Arg mutants in ARD domains suggested that other so-called non-canonical sites involving serine and threonine residues at positions - Ser44, Ser49, Ser155 (Ser157 in a 185-aa variant of HBc), Thr53 and Thr67 (Figure 1), could be potentially subjected to Ub-like modifications (Lubyova et al., 2017).

Although these findings altogether suggest that ubiquitination of core protein may play important role in its protein stability or HBV particle maturation and release, a direct link between particular E3 ubiquitin ligase and $\mathrm{HBc}$ ubiquitination is still missing and awaits future studies.

A potential involvement of other Ub-like modifications (e.g. SUMOylation, NEDDylation, or ISGylation) of HBc protein in HBV replication, virus maturation and release remain to be addressed.

\section{HBc and arginine methylation}

Arginine methylation is an important type of posttranslational modification that plays a role in a variety of biological processes including chromatin regulation, transcription control, RNA processing and nuclear transport (Bedford and Clarke, 2009; Bedford and Richard, 2005; McBride, 2006). Arginine methylation occurs on both nuclear and cytoplasmic proteins. This process is catalyzed by two major groups of protein arginine methyltransferases (PRMTs). Type I enzymes (PRMT1,2,3,4,6, and 8) catalyze production of monomethyl arginine (MMA) and asymmetric dimethylarginine (aDMA) and type II PRMTs (PRMT5,7,9) generate MMA and symmetric dimethylarginine (sDMA) (Blanc and Richard, 2017; Wolf, 2009). A major type II enzyme is PRMT5 that was identified and cloned as Jak2-binding protein and shown to methylate histones H2A, H3 and H4 (Branscombe et al., 2001; Pollack et al.,1999). It localizes to both the cytoplasm and the nucleus. In nucleus, PRMT5 catalyzes symmetric dimethylarginine of histone proteins to induce gene silencing by generating repressive histone marks, including H2AR3me2s, H3R8me2s, and H4R3me2s (Saha et al., 2016; Tee et al., 2010; Zhao et al., 2009). PRMT5 can also methylate nonhistone proteins such as the transcription factors including p53, E2F1 and p65 (Harris et al., 2016; Cho et al., 2012; Jansson et al., 2008). Mammalian PRMT5 is often found in complex with the WD-repeat protein MEP50 (also known as Wdr77, androgen receptor coactivator p44, or Valois) (Burgos et al., 2015). The major substrates of the cytosolic PRMT5/MEP50 complex are spliceosome proteins, Sm D1, D3, and B/B', and thus plays important role in splicing of mRNA (Stopa et al.,2015). PRMT5 and MEP50 were recently reported to interact with HBc in HepG2.2.15 cells and methylate two arginine residues within the Cterminally located arginine-rich domain (ARD) (Lubyova et al.,2017). Although, the HBc monomethylation predominantly occurred at arginine R154 (residue R156 for 185-aa HBc variant), the symmetric dimethylation was observed on both R150 and R154 (residues R150 and R156 for 185-aa variant of $\mathrm{HBC}$ ) (Fig. 1). It is also possible, that PRMT5 / MEP50 together with PRMT7 may co-operate in the methylation of $\mathrm{HBc}$ and regulate subcellular trafficking of $\mathrm{HBc}$ protein. While the monomethylated $\mathrm{HBc}$ was shown to be accumulated in the cytoplasm, symmetric dimethylation was demonstrated to be linked to serine phosphorylation and nuclear import of HBc (Lubyova et al., 2017).

In another study, PRMT5 was also shown to interact with HBc protein in transfected Huh7 cells. Zhang et al. (Zhang et al., 2017) reported that PRMT5 can restrict HBV replication through two mechanisms. First, PRMT5 epigenetically represses cccDNA transcription by promoting methylation of histone H4 (H4R3me2s). Second, PRMT5 independently of its catalytic activity interferes with encapsidation of pregenomic RNA and inhibits HBV core particle DNA production (Zhang et al., 2017).

\section{Conclusion and perspectives}

PTMs are capable of regulating protein function, either through creating new protein binding sites or by abrogating protein-protein interactions. Thus, combination of different PTMs would lead to multiple conformational changes of a single protein. Complexity of this phenomenon may further be enhanced by the fact that modifier protein itself can undergo posttranslational modifications. For example, ubiquitin and polyubiquitin chains were shown to be modified by some PTMs. These include phosphorylation, acetylation and modifications by the small ubiquitin-like (Ubl) modifier (SUMO) family (Hendriks et al., 2014; Lamoliatte et al., 2013; Olsen et al., 2006; Peng et al.,2003; Swaney et al.,2013; Swatek and Komander, 2016). Such modifications add another layer of complexity, regulation and functionality to ubiquitin signaling.

There is a growing evidence that PTMs of viral and cellular proteins play important role in regulation of many steps of viral life cycle. HBV is a small partially doublestranded circular DNA virus that encodes only a limited number of proteins. Hence, extensive PTMs of few viral proteins would contribute to unexpected diversity of virus-host interactions. 
Table 1. PTMs of $\mathrm{HBc}$ at a glance

\begin{tabular}{|c|c|c|c|}
\hline \multicolumn{4}{|c|}{ PTM: phosphorylation } \\
\hline Position & Enzyme & Mechanism/Function & Reference \\
\hline S87 & PKA & $\begin{array}{l}\text { PKA phosphorylates HBc in vitro and promotes capsid assembly } \\
\text { in HBV genotype C }\end{array}$ & (Kang et al., 2006) \\
\hline S106 & PKC & $\begin{array}{l}\text { PKC phosphorylates HBc in vitro and increases capsid assembly } \\
\text { and stability in HBV genotype C }\end{array}$ & (Kang et al., 2008) \\
\hline S155, S162, S170 & SRPK1/2 & Essential for RNA packaging and DNA synthesis & (Daub et al., 2002; Lan et al., 1999) \\
\hline S155, S162, S170 & CDK2 & $\begin{array}{l}\text { CDK2 is packaged into virions. Its activity can serve as a trigger } \\
\text { for PLK1-mediated phosphorylation }\end{array}$ & $\begin{array}{l}\text { (Diab et al.,2017; Ludgate et al.,2016; } \\
\text { Ludgate et al., 2012) }\end{array}$ \\
\hline $\begin{array}{l}\text { S155, T160, S162, } \\
\text { S168, S170, S176, } \\
\text { S178 }\end{array}$ & $\begin{array}{l}\text { SRPK1 } \\
\text { (PKA, PKC) }\end{array}$ & $\begin{array}{l}\text { SRPK1 phosphorylates all seven sites whereas PKA and/or PKC } \\
\text { phosphorylate fewer. Phosphorylation of all seven amino acids } \\
\text { reduced nonspecific RNA encapsidation, while specific partial } \\
\text { dephosphorylation enables selective pgRNA packaging. }\end{array}$ & (Heger-Stevic et al., 2018) \\
\hline S168, S176, S178 & PLK1 & $\begin{array}{l}\text { PLK1 directly interacts and phosphorylates HBc. Phosphoryla- } \\
\text { tion increases HBV replication and PLK1 siRNA knockdown sup- } \\
\text { presses HBV DNA synthesis. }\end{array}$ & (Diab et al., 2017) \\
\hline S44, T67, S141, S142 & n.d. & $\begin{array}{l}\text { Mass spectrometry analysis of wt HBc and ARD mutants de- } \\
\text { tected amino acids outside of CTD that may be subjected to } \\
\text { phosphorylation. }\end{array}$ & (Lubyova et al., 2017) \\
\hline n.d. & PKC & $\begin{array}{l}\text { Phosphorylation is important in later stages, after RNA en- } \\
\text { capsidation and virion assembly. PKC inhibitors affect virion } \\
\text { secretion but not genome maturation. }\end{array}$ & $\begin{array}{l}\text { (Kann and Gerlich, 1994; Wittkop } \\
\text { et al., 2010) }\end{array}$ \\
\hline n.d. & CK2 & CK2 activates PKAI $\alpha$ and PKAII $a$ in the absence of cAMP & (Enomoto et al., 2006) \\
\hline n.d. & $\begin{array}{l}\text { 46-kDA serine } \\
\text { kinase }\end{array}$ & HBc phosphorylation is essential for pgRNA encapsidation. & (Kau and Ting, 1998) \\
\hline n.d. & GAPD-PK & $\begin{array}{l}\text { Kinase phosphorylates core subunits and increases nuclear } \\
\text { transport of the viral genome. }\end{array}$ & (Duclos-Vallee et al., 1998) \\
\hline \multicolumn{4}{|c|}{ PTM: ubiquitination } \\
\hline Position & Enzyme & Mechanism/Function & Reference \\
\hline n.d. & $\begin{array}{l}\text { NIRF E3 li- } \\
\text { gase }\end{array}$ & $\begin{array}{l}\text { NIRF interacts with } \mathrm{HBc} \text { and targets } \mathrm{HBc} \text { for proteasome- } \\
\text { mediated degradation and inhibits HBV replication. }\end{array}$ & (Qian et al., 2012, 2015) \\
\hline K96 & $\begin{array}{l}\text { NEDD4 E3 } \\
\text { ligase }\end{array}$ & $\begin{array}{l}{ }_{129} \text { PPAY }^{132} \text { motif of HBc interacts with NEDD4, that may target } \\
\text { HBc for ubiquitination and facilitate HBV maturation and } \\
\text { release. }\end{array}$ & (Rost et al., 2006) \\
\hline $\begin{array}{l}\text { K7, S44, S49, S155, } \\
\text { T53, T67 }\end{array}$ & n.d. & $\begin{array}{l}\text { Mass spectrometry analysis of } w t \mathrm{HBc} \text { and ARD mutants de- } \\
\text { tected amino acids that may be subjected to Ub or other Ub-like } \\
\text { modifications. }\end{array}$ & (Lubyova et al., 2017) \\
\hline \multicolumn{4}{|c|}{ PTM: arginine methylation } \\
\hline Position & Enzyme & Mechanism/Function & Reference \\
\hline R150, R154 & $\begin{array}{l}\text { PRMT5/ } \\
\text { MEP50 }\end{array}$ & $\begin{array}{l}\text { PRMT5 and MEP50 interact with and methylate HBc protein. } \\
\text { HBc arginine methylation is thought to play role in regulation } \\
\text { of HBc subcellular trafficking. While MMA modification was } \\
\text { shown to be linked to cytoplasmic accumulation, sDMA was } \\
\text { predominantly demonstrated on nuclear HBc. }\end{array}$ & $\begin{array}{l}\text { (Lubyova et al., 2017; Zhang et al., } \\
\text { 2017) }\end{array}$ \\
\hline
\end{tabular}

The positions of modified residues correspond to amino acid sequence of a 183-aa variant of HBc. n.d. = not determined; MMA = monomethyl arginine; sDMA = symmetric dimethyl arginine.

Many studies of HBc phosphorylation (Table 1) showed that dynamic and tightly controlled steps between phosphorylation and de-phosphorylation events are critical for viral replication, encapsidation, DNA synthesis and virus maturation.

Recent reports also documented that UPS plays important role in regulation of HBV life cycle (Hu et al., 1999; Kong et al., 2019; Zhao et al., 2011). On one hand, the UPS as part of a host defense mechanism selectively recognizes viral proteins and induces their ubiquitin-dependent proteasomal degradation. On the other hand, the HBV has developed numerous strategies how to manipulate cellular UPS and use it for its own advantage. The polyubiquitination of $\mathrm{HBc}$ by NIRF E3 Ub-protein ligase promotes its degradation by ubiquitin proteasome pathway that leads to restricted viral replication. Conversely, NEDD4mediated ubiquitination may assist in viral maturation and release (Table 1). Nevertheless, a direct evidence of $\mathrm{HBc}$ ubiquitination is still missing and awaits future studies. It is possible that other Ubl modifiers, such as SUMO, 
NEDD8 or ISG15, also modify HBc protein. These potential HBc PTMs including acetylation, have not been studied yet and therefore remain to be addressed in the future.

Although the role of phosphorylation in the control of nuclear import has been widely documented, the importance of arginine methylation in subcellular localization is emerging only recently. PRMT5- and PRMT7mediated methylation of spliceosomal Sm proteins was demonstrated to facilitate assembly of functional spliceosome complex and localization into Cajal bodies in the nucleus (Gonsalvez et al., 2007; Yu, 2011). Likewise, the arginine methylation of cellular SF2/ASF protein, a member of the SR protein family, in conjunction with phosphorylation-dephosphorylation cycles was shown to play a role in the subcellular localization and trafficking of SF2/ASF (Sinha et al., 2010). The carboxy-terminus of $\mathrm{HBc}$ protein also undergoes controlled phosphorylation and de-phosphorylation events, which in combination with arginine methylation (Table 1) may result in various protein-protein interactions influencing its subcellular localization. Indeed, symmetric arginine dimethylation of $\mathrm{HBc}$ was demonstrated to be linked to increased serine phosphorylation and accumulation of $\mathrm{HBc}$ protein in nucleus (Lubyova et al., 2017).

In conclusion, the combination and co-operation of various PTMs affecting cellular and viral proteins may both promote or inhibit viral replication. Therefore, precise mapping, characterization and understanding the diversity of these PTMs would shed more light on the subject of virus-host interactions as well as be instrumental in the development of new effective antivirals.

Acknowledgment. This work was supported by ERDF/ESF project ChemBioDrug CZ.02.1.01/0.0/0.0/16_019/0000729.

\section{References}

Akutsu M, Dikic I, Bremm A., J. Cell Sci. 129, 875-880, 2016. https://doi.org/10.1242/ics.183954

Allweiss L, Dandri M., Viruses 9, 156, 2017. https://doi. org/10.3390/v9060156

Aviel S, Winberg G, Massucci M, Ciechanover A., J. Biol. Chem. 275, 23491, 2000. https://doi.org/10.1074/jbc. M002052200

Basagoudanavar SH, Perlman DH, Hu J., J. Virol. 81, 1641, 2007. https://doi.org/10.1128/JVI.01671-06

Beames B, Lanford RE., Virology 194, 597, 1993. https://doi. org/10.1006/viro.1993.1299

Bedford MT, Clarke SG., Mol. Cell 33, 1, 2009. https://doi. org/10.1016/j.molcel.2008.12.013

Bedford MT, Richard S., Mol. Cell 18, 263, 2005. https://doi. org/10.1016/j.molcel.2005.04.003
Birnbaum F, Nassal M., J. Virol. 64, 3319, 1990. https://doi. org/10.1128/JVI.64.7.3319-3330.1990

Blanc RS, Richard S., Mol. Cell 65, 8,2017. https://doi.org/10.1016/j. molcel.2016.11.003

Branscombe TL, Frankel A, Lee JH, Cook JR, Yang Z, Pestka S, Clarke S., J. Biol. Chem. 276, 32971, 2001. https://doi. org/10.1074/jbc.M105412200

Burgos ES, Wilczek C, Onikubo T, Bonanno JB, Jansong J, Reimer U, Shechter D., J. Biol. Chem. 290, 9674, 2015. https:// doi.org/10.1074/jbc.M115.636894

Chen C, Wang JC, Zlotnick A., PLoS Pathog. 7, e1002388, 2011. https://doi.org/10.1371/journal.ppat.1002388

Chiramel AI, Meyerson NR, McNally KL, Broeckel RM, Montoya VR, Mendez-Solis O, Robertson SJ, Sturdevant GL, Lubick KJ, Nair V, Youseff BH, Ireland RM, Bosio CM, Kim K, Luban J, Hirsch VM, Taylor RT, Bouamr F, Sawyer SL, Best SM., Cell. Rep. 27, 3269, 2019. https:// doi.org/10.1016/j.celrep.2019.05.040

Cho EC, Zheng S, Munro S, Liu G, Carr SM, Moehlenbrink J, Lu YC, Stimson L, Khan O, Konietzny R, McGouran J, Coutts AS, Kessler B, Kerr DJ, Thangue NB., EMBO J. 31, 1785, 2012. https://doi.org/10.1038/emboj.2012.17

Chong CK, Cheng CYS, Tsoi SYJ, Huang FY, Liu F, Seto WK, Lai CL, Yuen MF, Wong DK., Antiviral Res. 144, 1, 2017. https:// doi.org/10.1016/i.antiviral.2017.05.003

Chu TH, Liou AT, Su PY, Wu HN, Shih C., J. Virol. 88, 2530, 2014. https://doi.org/10.1128/JVI.03235-13

Chua PK, Tang FM, Huang JY, Suen CS, Shih C., J. Virol. 84, 2340, 2010. https://doi.org/10.1128/JVI.01666-09

Cohen P., Trends Biochem. Sci. 25, 596, 2000. https://doi. org/10.1016/S0968-0004(00)01712-6

Daub H, Blencke S, Habenberger P, Kurtenbach A, Dennenmoser J, Wissing J, Ullrich A, Cotten M., J. Virol. 76, 8124, 2002. https://doi.org/10.1128/JVI.76.16.8124-8137.2002

Diab A, Foca A, Fusil F, Lahlali T, Jalaguier P, Amirache F, N'Guyen L, Isorce N, Cosset FL, Zoulim F, Andrisani O, Durantel D., Hepatology 66, 1750, 2017. https://doi. org/10.1002/hep.29236

Diab A, Foca A, Zoulim F, Durantel D, Andrisani O., Antiviral Res. 149, 211, 2018. https://doi.org/10.1016/j.antiviral.2017.11.015

Duan G, Walther D., PLoS Comput. Biol .11, e1004049, 2015. https://doi.org/10.1371/journal.pcbi.1004049

Duclos-Vallee JC, Capel F, Mabit H, Petit MA., J. Gen. Virol. 79 ( Pt 7), 1665, 1998. https://doi.org/10.1099/0022-1317$\underline{79-7-1665}$

Enomoto M, Sawano Y, Kosuge S, Yamano Y, Kuroki K, Ohtsuki K., FEBS Lett. 580, 894, 2006. https://doi.org/10.1016/j. febslet.2006.01.011

Gallina A, Bonelli F, Zentilin L, Rindi G, Muttini M, Milanesi G., J. Virol. 63, 4645, 1989. https://doi.org/10.1128/ JVI.63.11.4645-4652.1989

Garcia ML, Byfield R, Robek MD., J.Virol. 83, 4923, 2009. https:// doi.org/10.1128/JVI.02644-08

Garcia ML, Reynolds TD, Mothes W, Robek MD., PLoS One 8, e72845, 2013. https://doi.org/10.1371/journal. pone. 0072845 
Gazina EV, Fielding JE, Lin B, Anderson DA., J. Virol. 74, 4721, 2000. https://doi.org/10.1128/JVI.74.10.4721-4728.2000

Gonsalvez GB, Tian L, Ospina JK, Boisvert FM, Lamond AI, Matera AG., J. Cell. Biol. 178, 733, 2007. https://doi. org $/ 10.1083 /$ jcb.200702147

Harris DP, Chandrasekharan UM, Bandyopadhyay S, Willard B, DiCorleto PE., PLoS One 11, e0148905, 2016. https://doi. org/10.1371/journal.pone.0148905

Hatton T, Zhou S, Standring DN., J. Virol. 66, 5232, 1992. https:// doi.org/10.1128/JVI.66.9.5232-5241.1992

Hayer J, Jadeau F, Deleage G, Kay A, Zoulim F, Combet C., Nucleic Acids Res. 41, D566, 2013. https://doi.org/10.1093/nar/ gks1022

Heger-Stevic J, Zimmermann P, Lecoq L, Bottcher B, Nassal M., PLoS Pathog.14, e1007488,2018. https://doi.org/10.1371/ journal.ppat.1007488

Hendriks IA, D'Souza RC, Yang B, Verlaan-de Vries M, Mann M, Vertegaal AC., Nat. Struct. Mol. Biol. 21, 927, 2014. https://doi.org/10.1038/nsmb.2890

Hershko A, Ciechanover A., Annu. Rev. Biochem. 67, 425, 1998. https://doi.org/10.1146/annurev.biochem.67.1.425

Hu Z, Zhang Z, Doo E, Coux O, Goldberg AL, Liang TJ., J. Virol. 73, 7231, 1999. https://doi.org/10.1128/JVI.73.9.7231$\underline{7240.1999}$

Jacob T, Van den Broeke C, Favoreel HW., J. Virol. 85, 1158, 2011. https://doi.org/10.1128/JVI.01369-10

Jakubiec A, Jupin I., Virus Res. 129, 73, 2007. https://doi. org/10.1016/j.virusres.2007.07.012

Jansson M, Durant ST, Cho EC, Sheahan S, Edelmann M, Kessler B, La Thangue NB., Nat. Cell. Biol.10,1431, 2008. https:// doi.org/10.1038/ncb1802

Jung J, Hwang SG, Chwae YJ, Park S, Shin HJ, Kim K., J. Virol. 88, 8754, 2014. https://doi.org/10.1128/JVI.01343-14

Kang H, Yu J, Jung G., Biochem. J. 416, 47, 2008. https://doi. org/10.1042/BJ20080724

Kang HY, Lee S, Park SG, Yu J, Kim Y, Jung G., Biochem. J. 398, 311, 2006. https://doi.org/10.1042/BJ20060347

Kann M, Gerlich WH., J. Virol. 68, 7993, 1994. https://doi. org/10.1128/JVI.68.12.7993-8000.1994

Kann M, Sodeik B, Vlachou A, Gerlich WH, Helenius A., J. Cell. Biol. 145, 45, 1999. https://doi.org/10.1083/jcb.145.1.45

Kau JH, Ting LP., J. Virol. 72, 3796, 1998. https://doi.org/10.1128/ JVI.72.5.3796-3803.1998

Keating JA, Striker R., Rev. Med. Virol. 22, 166, 2012. https://doi. org/10.1002/rmv.722

Kim JH, Kang S, Kim J, Ahn BY., J. Virol. 77, 7166, 2003. https:// doi.org/10.1128/JVI.77.13.7166-7173.2003

Kong F, You H, Kong D, Zheng K, Tang R., Virol. J. 16, 73, 2019. https://doi.org/10.1186/s12985-019-1183-z

Koniger C, Wingert I, Marsmann M, Rosler C, Beck J, Nassal M., Proc. Natl. Acad. Sci. USA 111, E4244, 2014. https://doi. org/10.1073/pnas.1409986111

Kravtsova-Ivantsiv Y, Ciechanover A., J. Cell. Sci. 125, 539, 2012. https://doi.org/10.1242/jcs.093567

Lamoliatte F, Bonneil E, Durette C, Caron-Lizotte O, Wildemann D, Zerweck J, Wenshuk H, Thibault P., Mol. Cell. Proteomics 12, 2536, 2013. https://doi.org/10.1074/mcp. $\underline{\mathrm{M} 112.025569}$
Lan YT, Li J, Liao W, Ou J., Virology 259, 342, 1999. https://doi. org/10.1006/viro.1999.9798

Lata S, Mishra R, Banerjea AC., Front Microbiol. 9, 2738, 2018. https://doi.org/10.3389/fmicb.2018.02738

Lavanchy D., J. Viral. Hepat.11, 97, 2004. https://doi.org/10.1046/ j.1365-2893.2003.00487.x

Lenard J., Pharmacol. Ther. 83,39,1999. https://doi.org/10.1016/ S0163-7258(99)00016-9

Lewellyn EB, Loeb DD., PLoS One 6, e17202, 2011. https://doi. org/10.1371/journal.pone.0017202

Li HC, Huang EY, Su PY, Wu SY, Yang CC, Lin YS, Chang WC, Shih C., PLoS Pathog. 6, e1001162, 2010. https://doi. org/10.1371/journal.ppat.1001162

Ling MT, Chiu YT, Lee TK, Leung SC, Fung MK, Wang X, Wong KF, Wong YC., J. Mol. Biol. 382, 34, 2008. https://doi. org/10.1016/j.jmb.2007.06.020

Liu K, Luckenbaugh L, Ning X, Xi J, Hu J., PLoS Pathog. 14, e1007085, 2018. https://doi.org/10.1371/journal. ppat.1007085

Liu K, Ludgate L, Yuan Z, Hu J., J. Virol. 89, 2918, 2015. https:// doi.org/10.1128/JVI.03116-14

Lubyova B, Hodek J, Zabransky A, Prouzova H, Hubalek M, Hirsch I, Weber J., PLoS One 12, e0186982, 2017. https:// doi.org/10.1371/journal.pone. 0186982

Ludgate L, Adams C, Hu J., PLoS One 6, e29566, 2011.https://doi. org/10.1371/journal.pone.0029566

Ludgate L, Liu K, Luckenbaugh L, Streck N, Eng S, Voitenleitner C, Delaney WEt, Hu J., J. Virol. 90, 5830, 2016. https:// doi.org/10.1128/JVI.00394-16

Ludgate L, Ning X, Nguyen DH, Adams C, Mentzer L, Hu J., J. Virol. 86,12237,2012. https://doi.org/10.1128/JVI.01218-12

Manning G, Whyte DB, Martinez R, Hunter T, Sudarsanam S., Science 298, 1912, 2002. https://doi.org/10.1126/science. 1075762

Mattiroli F, Sixma TK., Nat. Struct. Mol. Biol.21,308, 2014. https:// doi.org/10.1038/nsmb.2792

McBride AE., Enzymes 24, 51, 2006. https://doi.org/10.1016/ S1874-6047(06)80005-3

McClellan AJ, Laugesen SH, Ellgaard L., Open Biol. 9, 190147, 2019. https://doi.org/10.1098/rsob.190147

McDowell GS, Philpott A., Int J Biochem Cell. Biol. 45, 1833, 2013. https://doi.org/10.1016/j.biocel.2013.05.026

Melegari M, Wolf SK, Schneider RJ., J. Virol .79, 9810, 2005. https://doi.org/10.1128/JVI.79.15.9810-9820.2005

Mohd-Ismail NK, Lim Z, Gunaratne J, Tan YJ., Int. J. Mol. Sci. 20, 2019. https://doi.org/10.3390/ijms20174276

Nassal M., J. Virol. 66, 4107, 1992. https://doi.org/10.1128/ JVI.66.7.4107-4116.1992

Newman M, Chua PK, Tang FM, Su PY, Shih C., J. Virol. 83, 10616, 2009. https://doi.org/10.1128/JVI.00749-09

Ning X, Basagoudanavar SH, Liu K, Luckenbaugh L, Wei D, Wang C, Wei B, Zhao Y, Yan T, Delaney W, Hu J., J. Virol. 91, 2017. https://doi.org/10.1128/JVI.00092-17

Olsen JV, Blagoev B, Gnad F, Macek B, Kumar C, Mortensen P, Mann M., Cell 127, 635, 2006. https://doi.org/10.1016/i. cell.2006.09.026 
Peng J, Schwartz D, Elias JE, Thoreen CC, Cheng D, Marsischky G, Roelofs J, Finley D, Gygi SP., Nat. Biotechnol. 21, 921, 2003. https://doi.org/10.1038/nbt849

Perlman DH, Berg EA, O'Connor P B, Costello CE, Hu J., Proc. Natl. Acad. Sci. USA 102, 9020, 2005.

Pollack BP, Kotenko SV, He W, Izotova LS, Barnoski BL, Pestka S., J. Biol. Chem. 274, 31531, 1999. https://doi.org/10.1074/ jbc.274.44.31531

Pugh J, Zweidler A, Summers J., J. Virol. 63, 1371, 1989. https:// doi.org/10.1128/JVI.63.3.1371-1376.1989

Qian G, Hu B, Zhou D, Xuan Y, Bai L, Duan C., DNA Cell. Biol. 34, 327, 2015. https://doi.org/10.1089/dna.2014.2714

Qian G, Jin F, Chang L, Yang Y, Peng H, Duan C., Biotechnol. Lett. 34, 29, 2012. https://doi.org/10.1007/s10529-011-0751-0

Rabe B, Vlachou A, Pante N, Helenius A, Kann M., Proc. Natl. Acad.Sci.USA 100, 9849, 2003. https://doi.org/10.1073/ pnas. 1730940100

Ribet D, Cossart P., Cell 143, 694, 2010. https://doi.org/10.1016/j. cell.2010.11.019

Rost M, Mann S, Lambert C, Doring T, Thome N, Prange R., J. Biol. Chem. 281, 29297, 2006. https://doi.org/10.1074/ jbc.M603517200

Saha K, Adhikary G, Eckert RL., J. Invest. Dermatol.136, 214, 2016. https://doi.org/10.1038/JID.2015.400

Selzer L, Kant R, Wang JC, Bothner B, Zlotnick A., J. Biol. Chem. 290, 28584, 2015. https://doi.org/10.1074/jbc. M115.678441

Scheffner M, Nuber U, Huibregtse JM., Nature 373, 81, 1995. https://doi.org/10.1038/373081a0

Schmitz A, Schwarz A, Foss M, Zhou L, Rabe B, Hoellenriegel J, Stoeber M, Pante N, Kann M., PLoS Pathog 6, e1000741, 2010. https://doi.org/10.1371/journal.ppat.1000741

Sinha R, Allemand E, Zhang Z, Karni R, Myers MP, Krainer AR., Mol. Cell. Biol. 30, 2762, 2010. https://doi.org/10.1128/ MCB.01270-09

Stopa N, Krebs JE, Shechter D., Cell Mol. Life Sci. 72, 2041, 2015. https://doi.org/10.1007/s00018-015-1847-9

Su PY, Yang CJ, Chu TH, Chang CH, Chiang C, Tang FM, Lee CY, Shih C., Sci. Rep. 6,38959,2016. https://doi.org/10.1038/ srep38959

Swaney DL, Beltrao P, Starita L, Guo A, Rush J, Fields S, Krogan NJ, Villen J., Nat. Methods 10, 676, 2013. https://doi. org/10.1038/nmeth.2519

Swatek KN, Komander D., Cell. Res. 26, 399, 2016. https://doi. org/10.1038/cr.2016.39
Tee WW, Pardo M, Theunissen TW, Yu L, Choudhary JS, Hajkova P, Surani MA., Genes Dev. 24, 2772, 2010. https://doi. org/10.1101/gad.606110

Torres HA, Davila M., Nat. Rev. Clin. Oncol. 9, 156, 2012. https:// doi.org/10.1038/nrclinonc.2012.1

Wang JC, Dhason MS, Zlotnick A., PLoS Pathog. 8, e1002919, 2012. https://doi.org/10.1371/journal.ppat.1002919

Wang Z, Ni J, Li J, Shi B, Xu Y, Yuan Z., J. Virol. 85, 11457, 2011. https://doi.org/10.1128/JVI.00879-11

Wiborg O, Pedersen MS, Wind A, Berglund LE, Marcker KA, Vuust J., EMBO J. 4, 755, 1985. https://doi. org/10.1002/j.1460-2075.1985.tb03693.x

Wittkop L, Schwarz A, Cassany A, Grun-Bernhard S, Delaleau M, Rabe B, Cazenave C, Gerlich W, Glebe D, Kann M., Cell. Microbiol. 12, 962, 2010. https://doi.org/10.1111/i.14625822.2010.01444.x

Wolf SS.,Cell.Mol.Life Sci.66,2109,2009.https://doi.org/10.1007/ s00018-009-0010-x

Xiang A, Ren F, Lei X, Zhang J, Guo R, Lu Z, Guo Y., Antiviral Res. 120, 7, 2015. https://doi.org/10.1016/j.antiviral.2015.04.013

Yang F., Front Microbiol. 9, 2661, 2018. https://doi.org/10.3389/ fmicb.2018.02661

Yang HC, Kao JH., Emerg. Microbes Infect. 3, e64, 2014. https:// doi.org/10.1038/emi.2014.64

Yu MC., Mol. Biol. Int. 2011, 163827, 2011.

Zhang W, Chen J, Wu M, Zhang X, Zhang M, Yue L, Li Y, Liu J, Li B, Shen F, Wang Y, Bai L, Protzer U, Levrero M, Yuan Z., Hepatology 66, 398, 2017. https://doi.org/10.1002/ hep.29133

Zhao J, Wang C, Wang J, Yang X, Diao N, Li Q, Wang W, Xian L, Fang Z, Yu L., FEBS Lett. 585, 2943, 2011. https://doi. org/10.1016/j.febslet.2011.08.015

Zhao Q, Hu Z, Cheng J, Wu S, Luo Y, Chang J, Hu J, Guo JT., J. Virol 92, 2018. https://doi.org/10.1128/JVI.02139-17

Zhao Q, Rank G, Tan YT, Li H, Moritz RL, Simpson RJ, Cerruti L, Curtis DJ, Patel DJ, Allis CD, Cunningham JM, Jane SM., Nat. Struct. Mol. Biol. 16, 304, 2009. https://doi. org/10.1038/nsmb.1568

Zheng Y, Fu XD, Ou JH., Virology 342, 150, 2005. https://doi. org/10.1016/j.virol.2005.07.030

Zlotnick A, Venkatakrishnan B, Tan Z, Lewellyn E, Turner W, Francis S., Antiviral Res. 121, 82, 2015. https://doi. org/10.1016/j.antiviral.2015.06.020 